\title{
EVALUATION OF A NATIONAL SCHOOL DRUG EDUCATION PROGRAM IN AUSTRALIA
}

Richard Midford, Senior Research Fellow,

National Centre for Research into the Prevention of Drug Abuse

Nyanda McBride, Research Fellow,

National Centre for Research into the Prevention of Drug Abuse

Please address all correspondence to:

Richard Midford

Senior Research Fellow

National Centre for Research into the Prevention of Drug Abuse

Curtin University

GPO Box U1987

Perth WA 6845

Australia

Email: richard@ncrpda.curtin.edu.au

Manuscript revised 18/11/1998 


\begin{abstract}
The National Initiatives in Drug Education (NIDE) project was an initiative of the Australian Commonwealth government, to enhance school drug education in all Australian jurisdictions. The project was implemented in collaboration with States and Territories and primarily involved professional training for teachers of drug education and the development of teaching resources. The project was evaluated towards the end of its implementation period. An essentially descriptive approach was adopted, using several different investigative techniques to confirm the strength of evidence and build a global picture. While there are inherent limitations to such a retrospective approach, considerable insight was gained as to the achievements of the project. In an overall sense, people in all jurisdictions, at all levels of involvement in drug education, considered NIDE a beneficial project. NIDE increased the quantity and quality of drug education. The teaching resource materials developed by NIDE were generally well regarded. The process of implementation was respectful and empowering. State and Territory representatives felt part of a coherent national project. The harm minimisation premise of the project was well accepted. NIDE also had a number of limitations, but it has contributed in a major way to the ongoing evolution of school drug education in Australia.
\end{abstract}

\title{
THE DEVELOPMENT OF THE PROJECT
}

The National Initiatives in Drug Education (NIDE) project was a national initiative designed to enhance school drug education in all Australian States and Territories. The project and its subsequent evaluation had its origins in the National Drug Strategic Plan, which identified drug education in schools as a priority activity and made a commitment to develop a core set of educational resources (National Drug Strategy Committee, 1993). The then Commonwealth Department of Human Services and Health had responsibility for implementing this aspect of national drug strategy and during 1993 and 1994 a series of exploratory meetings were held between senior Commonwealth drug strategy officials and State/Territory managers with responsibility for drug education in schools. A consistent theme at these meetings was the need to provide a sizeable amount of dedicated funding to galvanise action at the State level and support this with coherent concepts, structures and resources.

In 1995, the Commonwealth commissioned a school drug education needs assessment (Morris and Mellor, 1995). This formal analysis confirmed and integrated much of the anecdotal feedback on 
what was required to achieve effective drug education and was used as the basis for planning the NIDE project. A National Steering Committee was established to consider the findings of the needs assessment and to provide a platform for consultation and collaboration, between Commonwealth and State/Territory service sectors with a stake in drug education. This group unanimously agreed that priority should be given to professional development training for teachers of drug education, although a range of other needs would also be addressed by the project.

The aim of NIDE, as expressed in its mission Statement was as follows:

National NIDE Steering Committee and State and Territory agencies working collaboratively to improve drug education for young people (National Initiatives in Drug Education (NIDE), undated, p 2).

This collaborative approach was reinforced by an early commitment to implement the NIDE project goals through current State/Territory infrastructure. In addition, a national forum was conducted in Canberra during June 1995, which brought together 150 participants representing government and non-government schools, health and police service sectors and other relevant agencies, from all Australian jurisdictions. This forum was seminal in that it enunciated, demonstrated and disseminated the NIDE agenda to key state-level stakeholders. Following the National Forum, States and Territories were invited to submit proposals to access NIDE funding, the criteria for which were jointly set to reflect priority areas. In broad terms there were three phases to the implementation of NIDE at the state-level, although the Commonwealth simultaneously developed and disseminated a number of resources which were used in professional development and classroom teaching. 
Phase One: This focused on training in drug education for teachers and other personnel involved in dealing with school drug issues, such as schools nurses, counsellors and community health workers. Activities occurred in late 1995/early 1996.

Phase Two: This focused on fostering community based drug education. Activities occurred during mid 1996.

Phase Three: This encompassed a broad spectrum of initiatives designed to reinforce earlier professional development and foster a whole of school approach to drug issues. Areas covered included: developing approaches to suit local needs, sustainability, community and parent links, extended professional development and sharing of best practice models. Activities occurred during 1997.

The NIDE project was a major drug education initiative, implemented over a period of several years in all Australian jurisdictions. It had a variety of components and the activity it fostered in the different jurisdictions varied according to local needs and pre-existing drug education projects. However, the NIDE project had a number of specific objectives and there were unifying themes and common components in its implementation. As the project was nearing completion, the responsible Commonwealth Department, Health and Family Services, made the decision to evaluate the project in terms of achievement of its original objectives. 
The NIDE evaluation was required to address seven specific terms of reference. This was a technical requirement for assessing how the project addressed a range of stated goals. However, in the interest of providing a more succinct assessment of what can be achieved by a national drug education project, this paper will focus on the evaluation's findings in relation to the first and main term of reference:

Determine the effectiveness of the NIDE project as a whole, in its ability to deliver against the Stated objectives of the project (National Initiatives in Drug Education, undated, p. 2)

A number of jurisdictions had existing drug education programs that were complemented by NIDE. Some jurisdictions emphasised a broad approach in implementing NIDE, where a certain amount of teacher training was offered to all schools. Others concentrated on providing in-service training for a greater proportion of the teachers in a small number of focus schools, followed by intense whole of school development, focussing on drug education. There was no typical profile of how NIDE was implemented and jurisdictions altered the emphasis of their activity during the course of the project to suit their changing needs. A commitment to harm minimisation was probably the most consistent aspect of NIDE activity.

In seeking to understand why implementation of NIDE was quite different across jurisdictions, it is important to take into consideration that each was at a different point in developing its approach to drug education. Consequently, NIDE had to fit in with the approach already being undertaken. In some cases, NIDE was used to complement and extend existing programs and took a certain form because of this. In other cases, NIDE provided an opportunity to initiate drug education and implementation options were less constrained.

Table 1 summarises the main differences in the implementation of NIDE between jurisdictions. 


\section{Place table 1 about here}

\section{EVALUATION METHODOLOGY}

\section{Determinants of Methodology}

Decisions concerning the methodology adopted to evaluate NIDE were determined strongly by the fact that the project had already been implemented. This factor limited the opportunity to adopt a quasi-experimental research design. Instead, qualitative methodologies providing descriptive information from key informants formed the basis of the evaluation. Three levels of key informants were identified: management level key informants; project officer/trainer level key informants and school-based (predominantly teacher) level key informants. Project documents and limited, indicative survey sampling were also used to provide greater breadth of data. The approach blended techniques from two investigative methods designed for naturalistic settings, Dennis's (Hage et al, 1976) 'Precision Journalism', and Parlett and Hamilton's (1972) 'Illuminative Model'. This has been termed 'triangulation' by Guba and Lincoln (1981), because the global understanding of what has occurred derives from several different investigation components.

\section{Evaluation Activities}

Initially, in-depth, structured interviews were conducted with relevant Commonwealth officers involved with the project and manager, steering committee, and project officer/trainer level key 
informants in all States and Territories. Supporting documentation was also gathered. This process was used to understand how the project developed and to identify implementation processes and key issues on a state by state basis. Face-to-face interviews with the following categories of key representatives were sought within each jurisdiction, although in some cases there was no suitable representative to interview, or a telephone interview had to be conducted.

Manager level

$$
\begin{aligned}
& \text { Government education system representative } \\
& \text { Catholic education system representative } \\
& \text { Independent Schools sector representative } \\
& \text { Police department representative } \\
& \text { Health organisation representative }
\end{aligned}
$$

\section{Project officer/trainer level Representative responsible for NIDE teacher training Representative responsible for NIDE community action projects}

Additional key informants, other than those from the categories listed above, were interviewed when they were identified as being able to offer extra information.

The Commonwealth's terms of reference for the evaluation and preliminary telephone conversations with each jurisdiction's manager level key informants formed the basis for the key questions and prompts used in the structured interview process. However, there was also scope for specific issues to be identified and discussed. Where possible, key informants were sent a copy of the interview questions prior to interview.

Accessing information at the school level was always considered an integral component of the NIDE evaluation, but time and resources had to be managed judiciously. Accordingly, 
complementary qualitative and quantitative approaches were used as a way of obtaining some specific detail as to how NIDE was implemented in schools and gaining an indication of the breadth of the project's impact at the school level.

\section{Focus Groups}

Focus groups, predominantly comprised of teachers, were used to gather qualitative data on how NIDE was incorporated at the school level. A standard suite of questions, pertaining to the evaluation's terms of reference, was asked in every group, but there was ample opportunity for discussion of the issues raised. This method of gathering data was chosen because it can identify repeated themes, provide some sense of what was considered most important and gives insight as to the implementation of NIDE at the school level (Hawe, Degeling and Hall, 1992). Participants were invited from government and non-government schools, roughly in proportion to their share of a jurisdiction's enrolments, but other factors such as availability, enthusiasm and venue meant that the make up of most groups varied from the ideal. The smallest focus group comprised five participants; the largest comprised nine. One focus group was conducted in the capital city of each jurisdiction. An additional focus group was conducted in the regional Queensland city of Toowoomba.

\section{Teacher Survey}

A brief teacher survey, addressing relevant evaluation goals, was conducted in all jurisdictions. There was some stratification of the sample by State, school sector/system, and rurality, with deliberate over sampling of teachers from small jurisdictions and non-metropolitan schools. Jurisdictions, which concentrated NIDE activity in focus schools, were under sampled, because of the fewer number of teachers exposed to NIDE. Table 2 indicates that the profile of the respondent group matches the intention fairly well, although Victoria was not well represented due to non participation by the State education department. In the Northern Territory the reverse 
occurred, as the response rate was very high. The overall response rate of $62.5 \%$ is good for this type of survey. However, care should be taken in interpreting the data, because of a number of limitations, which are presented in the next section of the report.

\section{Place Table 2 about here}

\section{LIMITATIONS OF THE EVALUATION}

The NIDE project evaluation was conducted retrospectively and an essentially descriptive approach was adopted, using several different investigative techniques to confirm the strength of evidence and build a global picture. Although each method in isolation has associated limitations, together they help to reinforce the accuracy of the evaluation findings, increasing confidence that the influence of the NIDE project on project participants/schools is real and different from other drug education activity conducted during the same period. 
Focus groups were purposely selected as a method of data gathering for the NIDE evaluation, in order to increase the scope for qualitative input by teacher participants. However, the following limitations are salient.

- The three most populous States (NSW, Queensland, Victoria) used NIDE funds to provide widespread teacher training, rather than a focus school approach and attempts were made to conduct two focus groups in each State. However, in two States (NSW, Victoria) the second focus group did not eventuate because of organisational constraints.

- At times, focus groups did not achieve the desired proportional representation of government and non-government teachers due to suitable teachers not being available or invited teachers being unable to attend.

Some stratification of the survey sample was undertaken. However, the percentage of teachers involved in NIDE activity varied in each jurisdiction and the response rate varied considerably between jurisdictions. This means that the survey sample should essentially be considered a sample of convenience. In addition, the following limitations were associated with this evaluation component.

- Permission from the Victorian government education system to conduct the survey with their teachers was not obtained within the time period allocated for this task.

- School holidays in Tasmania reduced the amount of time teachers in this State had to complete and return surveys. 
- Departmental permission and subsequent organisation of teacher mail-outs were delayed in New South Wales.

- Movement of teachers from project schools reduced total numbers

\section{FINDINGS}

Data has been amalgamated from all sources in order to determine how the NIDE project responded to the specific objectives contained within its main term of reference. Each objective is presented below as a heading and relevant findings are grouped accordingly.

\section{Utilisation of Best Practice}

In determining the extent to which NIDE utilised best practice strategies, the bench marks used were the 15 principles contained in "Principles for Drug Education in Schools" (Ballard, Gillespie and Irwin, 1994). This document grew out of experience gained from the School Development in Health Education (SDHE) project and is a succinct, evidence based summary of best practice principles. As a way of structuring the findings in relation to this objective, summary statements of relevant best practice, which derive from Ballard, Gillespie and Irwin (1994) are presented as headings. Findings that pertain to how well NIDE has addressed each issue are then grouped under the relevant heading.

\section{Drug education should be taught in the context of the school health curriculum}

In those States that focused on development and implementation of a drug education curriculum, this was done in the context of the school health curriculum, which encompasses developmentally sequenced, classroom teaching of all health related material such as sexuality, communicable diseases and prevention of lifestyle health problems. The benefits of integration, continuity and 
context that derive from such an approach were clearly appreciated by stakeholders at every level. South Australia, for example, required all focus schools to develop a drug education program, in the context of a health curriculum. These documents were then published and disseminated to all schools in the State. Focus group discussions suggested that schools were at varying points in the development of their health curriculum. Some schools had a well-developed health curriculum, whereas other schools used their involvement with NIDE as a springboard from which to initiate health education and as part of that, a drug education program.

\section{Drug Education should be conducted by health teachers}

The widely implemented teacher training component of NIDE was based on a train-the-trainer model and was successful in skilling considerable numbers of teachers in most jurisdictions. In Queensland, for example, 1900 teachers were provided with training in drug education during 1995/96 as a result of NIDE funding (Ballard, undated). In NSW, 40 district level drug education workshops were conducted during 1995/96 to provide training for two teachers from every government central and high school in the State (NSW Management Committee, undated). Most of these teachers were from the health and physical education area, but the focus groups indicated that a considerable proportion were other teachers with an interest in the area. The teacher survey responses indicated that $44 \%$ of the respondents had participated in external professional development and training and 33\% had participated in school based development/training, they knew was generated by NIDE. A further $41 \%$ had participated in other drug education training activities during the last year, which may or may not have been generated by NIDE. This indicates widespread exposure to drug education, most of which can be explicitly identified as emanating from NIDE.

Drug education should be sequential, progressive and continuous with long term positive outcomes 
This has not been well achieved by NIDE in a strategic sense, because it was a 'one off' project. There were repeated comments from all sources that on-going funding is required to initiate and maintain an integrated approach to drug issues at the school level. The general sense conveyed, particularly from the focus groups, was that the NIDE project has greatly assisted schools develop good practice in relation to drug education, but that unless the input is maintained, practice will deteriorate with turnover of trained staff.

Drug education messages should be consistent, coherent and linked to the goal of harm minimisation

NIDE essentially promoted a harm minimisation message in all jurisdictions, although Western Australia gave more emphasis to abstinence strategies. In this respect, the drug education conducted as part of NIDE was consistent. It should also be considered coherent, because the harm minimisation premise is evidence based and widely considered logical and appropriate. Harm minimisation was considered a useful strategy by six of the nine focus groups. However, some focus group teachers commented that the way harm minimisation was presented to school staff and parents was critical in determining its acceptance. If it was well presented and included non-use as an option, then the concept was understood and accepted as a realistic approach. If the concept was not presented well, then concerns remained and support for the concept was questionable. The teachers surveyed also indicated strong support for harm minimisation, with 75\% either agreeing or strongly agreeing that it was a good approach for school drug education.

\section{Drug education should emphasise drug use that is relevant to the target group}

The teaching resources developed by NIDE and the training delivered at a State and Territory level clearly focused on current drug use patterns and those drugs which cause the most harms. In developing the approach to be taken, Commonwealth officers with responsibility for implementing NIDE consulted extensively with State and Territory stakeholders at management, 
trainer and teacher levels in order to ensure that NIDE resources and service delivery approaches met the needs of these stakeholders. Several teachers in the focus groups considered that more weight should be given to statistical data on student drug use in determining the emphasis of drug education programs, rather than just basing decisions on teacher perceptions of student needs.

Drug education should address the values attitudes and behaviours of the community and the individual and involve students, parents and the wider community in program

This occurred in some schools, particularly those in jurisdictions that had a distinct parent and community component such as the Northern Territory and those States that adopted a focus school approach, such as Tasmania. Training and other involvement tended to focus on parents, however, focus group participants repeatedly commented that even engaging this group was difficult and methods to foster greater parental involvement in drug education need to be developed. Most focus groups commented that they had increased community involvement in the delivery of drug education, however, this generally involved a school talk by a person with specialised drug knowledge. Only $10 \%$ of survey respondents had participated in a NIDE community based drug education forum, with slightly more (15\%) indicating they had participated in a local parent/community forum not known to be generated by NIDE. This suggests a low rate of community involvement in NIDE.

Drug education should reflect proven methodology, the interrelationship of use factors and the diversity of student needs deriving from factors such as culture, gender and stage of development NIDE drug education generally addressed these best practice principles well. The NIDE project incorporated extensive consultation with key stakeholders, used objective data on student drug use patterns and had skilled people at the manager and project officer/trainer level involved in organising and delivering training. NIDE activity was also incorporated into existing structures and services so it could take local issues into consideration. An example of this was provided by a 
key informant from the Association of Independent Schools in NSW, who indicated that NIDE had been well received by independent schools because different aspects of the program were matched to the needs of each school.

There was some criticism of the NIDE resources from teachers, project officer/trainers and State steering committee members in regard to their appropriateness for regional Australia and Aboriginal people. Some comments from focus groups suggested the need for more student involvement in resource development and more recognition of the particular needs of remote schools.

\section{Drug education should be evaluated}

The NIDE evaluation report in itself is evidence of a commitment by the NIDE project to evaluation (Midford and McBride, 1997). However, better information would come from evaluation that was incorporated at project inception. In addition to evaluation of the project as a whole, various jurisdictions undertook evaluation of component activities such as a community forum. Western Australia was the only jurisdiction that undertook a comprehensive local evaluation of the NIDE project using a quasi-experimental paradigm that permitted clear identification of change achieved by NIDE (McBride and Midford, 1997).

\section{Provision of comprehensive, up to date and high quality national drug education resources}

Most key informants at the manager and project officer/trainer level commented that training in resource use was essential to effective implementation of NIDE. Provision of free, up to date resources by NIDE was considered to be a particularly attractive aspect of the project. However, in many cases, NIDE resources were not available or had not been finalised when teacher training 
was conducted. Subsequent to training, distribution of resources was often slow. Both these factors were seen as detrimental to effective implementation.

The NIDE resource package developed by the Commonwealth, which involved the greatest amount of consultation, was the 'Do It' series of four booklets (Commonwealth Department of Human Services and Health, 1996a). These were designed to provide guidelines for drug education curriculum development, teacher training, involvement of community agencies and selection of education resources for drug education project officer/trainers and others supporting drug education in schools. In these terms, the booklets were acknowledged as useful general references. However, key informants stated that they were not widely used, because they were considered to be of limited use in the actual conduct of drug education and to be more relevant for policy development.

The other NIDE resources were designed to be used more directly in providing drug education and as a consequence respondents at all levels were familiar with them. Key informants considered that the video, 'Harm Minimisation: An Approach for Australian Schools' (Australian Drug Foundation, 1996), was useful in explaining the concept to teachers and parents, but needed to be followed by discussion to clarify any issues of concern. 'Candidly Cannabis' (Commonwealth Department of Health and Family Services, 1996b) was considered a good resource, primarily because it was the first of its kind, but comments indicated that resources in this area need to be further refined. 'How Will You Feel Tomorrow' (Commonwealth Department of Health and Family Services, 1996c), an alcohol information kit, was considered to be an adequate resource, but its impact was diminished because a similar privately funded resource became available at the same time. 
The following table indicates the percentage of teachers surveyed who knew of the above mentioned drug education resources and how they rated them.

\section{Place Table 3 about here}

These figures tend to confirm the information received from the focus groups. Resources not designed for classroom use were not well known to teachers. Classroom resources were well known and well regarded.

\section{Enhanced access to professional development for teachers}

A considerable amount of data from different sources indicate that NIDE did enhance both the quality and quantity of professional development for teachers, although the extent of change cannot be gauged, because baseline measures were not taken. As indicated previously, NIDE drug education was consciously designed to reflect best practice principles in regard to content and process and an aspect of best practice that was universally adopted was training teachers to conduct drug education. NIDE funding also enabled more teacher training to occur in all jurisdictions. In South Australia, Tasmania and Western Australia, where a focus school approach was used from the outset, a considerably greater amount of professional development was provided to the selected focus schools. Sixty five percent of respondents from these States commented that they had attended centrally conducted NIDE training. This response rate was considerably higher than that obtained from other States where teacher training was more broadly 
spread. Here $27 \%$ of respondents commented that they had attended centrally conducted NIDE teacher training.

\section{Enrichment of approaches through opportunities for national collaboration}

National consultation and collaboration was integral to the initial stages of NIDE. Comments from key informants, who attended national planning meetings and/or the June 1995 Canberra Forum, indicate that they felt part of an innovative national approach to drug education. However, only $4 \%$ of the teachers surveyed attended the Canberra forum and subsequent to this event there were no national events involving even moderate numbers of people in the drug education area. The ACT sent a number of people to a NIDE professional development course conducted in Sydney in June 1996. The ACT Catholic education system's diocesan health advisor was also part of the larger NSW network of diocesan health advisors. However, apart from these bilateral arrangements, NIDE activities have essentially been compartmentalised on the basis of jurisdictional boundaries.

Some focus group teachers thought that participation in a national project gave drug education a better image in their school and that it validated the importance of their work, particularly with school administrators. Most focus groups commented that networking between teachers was important, but this only seemed to occur at a local level. Community forums were useful for making contacts and establishing networks, as were regional education workshops. A commitment to drug education by a cluster of schools was also seen as useful, because it provided mutual support and meant that individual schools were not seen as having a particular problem with drugs. 
This aspect of the NIDE project was given greatest emphasis during Phase Two, which was specifically designed to foster community based drug education initiatives or community action projects. However, not all jurisdictions participated in Phase Two (see Table 1) and the activities did not necessarily integrate well with school focused NIDE activities.

In Tasmania, Phase Two funding was directed towards community action, supportive of school drug education. This component of NIDE provided for small grant allocations to groups who expressed interest and who met predetermined criteria. In Victoria, Phase Two activity was more elaborate and involved providing funding to community drug education support for schools and employment of a project officer/trainer to undertake community activity.

All other jurisdictions either did not receive Phase Two funding or undertook community activity that was essentially integrated into the broader NIDE program. Queensland and the Northern Territory, for instance, undertook a series of community and parent forums designed to create awareness of the drug education programs being conducted in their respective jurisdictions and facilitate local level networks that teachers could draw on to support school based activity.

The focus group respondents were generally aware of the crucial role played by a school's community is determining students' patterns of drug use. However, discussion concentrated on ways of involving parents, rather than the broader community, as this was considered a major undertaking in itself.

Increased ability to implement quality primary intervention/prevention strategies that are broad broad-based and comprehensive 
NIDE has enabled the establishment of a crucial decision making body in each jurisdiction to facilitate this broad approach to drug education, the NIDE State steering committee. These committees have been useful in reshaping how drug education is conceptualised and undertaken, but it must be remembered that the NIDE project has only been underway since 1995 and global, system level changes take a while to implement, let alone assess. Accordingly, NIDE achievements in this area have been limited and have focused on changing drug education practice in schools. What has been done has also been poorly documented, which inhibits model building, refinement and dissemination. Aspects of Phase Two activity in some jurisdictions could be counted as having addressed this objective and jurisdictions which took a focus school approach were able to implement more comprehensive prevention programs at the school level. However, approaches tended to be circumscribed and/or time limited. Community drug education forums conducted in several jurisdictions have been useful in raising the profile of drug education and have acted as a catalyst for the development of local professional networks. These events tended to have their greatest impact at the local level and have not contributed greatly to broad strategic change, although the Northern Territory did foster media coverage of their community forums which resulted in broader dissemination of drug education messages.

Table 4 summarises the information provided by the focus groups as to 'What did your school do' in the way of prevention activity.

\section{Place Table 4 about here}




\section{Support to increase the number of schools delivering quality school-based drug education programs within a health promotion framework}

A health promotion framework was considered to exist within schools if there had been development of a range of complementary activities that reinforced drug education messages. The broad areas of activity included in this assessment were: curriculum development and delivery; policy development; parental involvement and wider community involvement. Based on these criteria, three jurisdictions (see Table 1) used NIDE resources to develop drug education activity in focus schools. However, focus groups indicated that individual schools in other States that implemented a more widespread, but less intense approach, also adopted a whole of school approach to drug education. In such cases, it is not possible to distinguish between the influence of NIDE and the influence of other sources. Overall, 33\% of survey respondents commented that their school had some level of NIDE school based planning activity (policy, curriculum development etc.). When this data was analysed by the approach taken at a State level it was clear that a focus school approach was more effective in encouraging more diverse drug education activity. Seventy percent of focus school respondents indicated that school based planning activity (policy, curriculum development etc.) occurred; whereas only 32\% of respondents in States that adopted a widespread approach indicated planning for a diverse range of drug education activity. Forty six percent of teacher respondents in States that adopted a combined approach indicated that school based planning activity (policy, curriculum development etc.) occurred.

Seven out of the nine focus groups indicated that NIDE promoted a whole of school approach to drug education, indicating that NIDE training included this concept. The fact that this approach did not get translated into action in all cases, even though it was considered important, may have been due to other aspects of NIDE being given priority; for example, the development a drug education curriculum, where none existed prior to NIDE. 


\section{Opportunities for police, health and education to co-ordinate their activities at the community level}

All jurisdictions had project steering committees that included representatives from the police and health sectors. At a senior level this ensured good exchange of information, development of a shared understanding of drug education and co-ordination of approaches. In the Northern Territory, police and health personnel were regularly involved in delivery of training at the school level, as their local availability meant training could occur without incurring additional travel costs for dedicated presenters. Laying the foundation for this to occur as part of a best practice model involved considerable prior negotiation to define the degree of involvement and the approaches to be adopted. In other jurisdictions, there was local involvement of police and health representatives, which tended to be arranged on a event by event basis. Teacher comments indicate that it was useful to have representatives from these groups at training sessions, as it assisted in the identification of resources that were available in the community to assist in drug education. However, there was general hesitancy to routinely involve police in the delivery of drug education in schools, because of the inherent emphasis this gives to the law enforcement aspect of drug use. In addition to establishing contacts through teacher training sessions, a central project officer/trainer was considered useful in facilitating contact between community agencies and schools after the training workshop, especially in those States that adopted a focus school approach. Teachers in five of the focus groups commented that inviting guest speakers to the school was useful as a way of 'spicing up' drug education lessons, but that they usually fitted these talks within a planned curriculum rather than as a replacement for school level drug education

\section{SUMMARY DISCUSSION}


A strong impression, gained during the course of the evaluation, was the enthusiasm and goodwill that existed towards the NIDE project across all jurisdictions and at all levels. Considerable assistance with the evaluation was provided by State level managers and drug education training officers. Teachers were also extremely generous in their assistance, which in some ways was more surprising, because their involvement in NIDE would not have been a core aspect of their normal work. This generosity of contribution adds a further dimension to the specific data on NIDE presented in the previous section. In a more diffuse way it confirms that people at all levels of involvement in drug education, considered NIDE beneficial and worthy of support.

It is important to emphasise that the NIDE implementation process was central to its acceptance, because it was respectful and empowering. Joint decision making structures were established. The Commonwealth took into consideration that NIDE needed to be integrated into existing service delivery structures and build on drug education already being undertaken. There was a willingness to get stakeholders together to achieve consensus on major decisions. These processes were modelled in the initial dealings with the States and Territories and tended to be adopted at all levels of implementation.

The NIDE processes were complimented by some inherent project qualities that contributed to a positive reception at the State level. State representatives felt part of a coherent national project with a premise that was evidence based and well accepted: harm minimisation. National participation was also a plus for school-based participants. Teachers commented that NIDE's impact was greater, because it provided a 'big picture' approach rather than the usual focus on isolated local school action. At all levels it was considered that a national approach generated a high level of support for drug education, made drug education more systematic and tied it to a evidence based national standards. The decision to allocate funding directly to the education sector was also seen in a positive light, because it allowed greater control in determining strategies 
that would be sympathetic to an education culture and particularly suit each sector/system. Feedback indicated that in those jurisdictions with an existing drug education program, NIDE funding permitted expansion and increased efficiency, whereas those jurisdictions that did not have an existing drug education program were able to take advantage of being included in a larger project.

While NIDE was generally viewed positively, there were a number of common concerns expressed across jurisdictions. One of the main concerns expressed at management, project implementation and teacher levels was that implementation planning timelines were too short to be functional. There was also a sense that significant change in the way drug education is conducted will not occur in one or two years. NIDE has contributed substantially to the extension and maintenance of drug education in most jurisdictions, but forward planning and on-going support are required to maintain momentum.

Turnover of key staff with responsibility for implementation of NIDE was mentioned repeatedly as a factor that hindered the project, because of the loss of corporate memory and expertise. Teacher turnover was seen as a similar problem and the issue of staff continuity at all levels should be addressed in any future initiatives.

It is difficult to definitively say what NIDE achieved, because NIDE was implemented quite differently in each jurisdiction and in many cases the funding provided by the Commonwealth was supplemented by State funding. In Western Australia, a quasi-experimental evaluation, of the State's drug education program in 1996, which incorporated NIDE funding, indicated significant participant and school level change (McBride and Midford, 1997). However, this State level prospective evaluation is unique. What is clear from the information gathered retrospectively from 
all jurisdictions is that the aggregate level of drug education activity increased in Australia over the last couple of years and that this activity was grounded in best practice.

In some jurisdictions, activity was focused on selected schools, in others, activity was spread more evenly across most schools. Some jurisdictions employed each model at different phases of the project (see Table 1). Results, particularly from the teacher survey indicate that the focus school approach achieved a greater level of change in the schools where it operated. However, because of the concentration of resources, only relatively few schools could benefit from this approach. The widespread approach seems to have achieved less change, but in a greater number of schools. The focused approach represents a coincidence of best practice features as indicated in the implementation of the School Development in Health Education project (Ballard et al, 1994, Irwin et al, 1991), however, it will probably always be limited in its application, because of the resource implications. The widespread approach does not well represent best practice and it effects may be quite dilute, because a critical mass of support is less likely to be created at a school level. However, its reach, while less intense, is greater and more schools are able to access some level of drug education training.

The choice as to which model or approach to adopt is probably best determined by the objectives of the program, whether that be reach or intensity. A mixed model approach may be useful in those jurisdictions that have schools at varying levels of development. Those schools that have done some prior work in drug education and are keen to do more will be prepared for an intense approach, whereas schools that have had little drug education may be best served by broad based teacher training. This may create interest and increase knowledge and skill in preparation for further development. 
What does seem clear about NIDE is that it is a distinct phase in the ongoing evolution of school drug education in Australia. It has provided the opportunity for States to build on lessons learnt from previous projects and in itself will provide lessons to guide future projects. However, the continuity of drug education in Australia is fundamentally an issue of funding. Funding is needed to provide support infrastructure and training, to develop education resources, but most of all, funding is needed to buy staff time. If teachers and other school staff are to take on a best practice approach to drug education they need to have the time to do it, away from their normal duties: time to be trained; time to achieve school level support for the development of drug education; time to plan whole of school activities and time to implement planned activity. If drug education is to be an ongoing national priority, continuity of adequate funding is essential.

\section{REFERENCES}

Australian Drug Foundation (1996) Harm Minimisation: An Approach for Australian Schools. Canberra: Commonwealth Department of Health and Family Services.

Ballard R, Gillespie A, Irwin R (1994) Principles for drug education in schools. Canberra: University of Canberra.

Commonwealth Department of Human Services and Health (1996a) Drug Education: Do It. Canberra: Author.

Commonwealth Department of Human Services and Health (1996b) Candidly Cannabis. Canberra: Author. 
Commonwealth Department of Human Services and Health (1996c) How Will You Feel Tomorrow. Canberra: Author.

Guba EG, Lincoln YS (1981) Effective Evaluation. Jossey-Bass: San Francisco.

Hage GS, Dennis EE, Ismach AH, Harten S (1976) New Strategies for Public Affairs Reporting. Englewood Cliffs, NJ: Prentice Hall.

Hawe P, Degeling D, Hall J (1992) Evaluating Health Promotion A Health Worker's Guide. Sydney: Maclennan and Petty.

Irwin R, Ansell D, Ballard R, Benjamin M, Grant M, Blackaby B, Hicks J, Jones D, Kerr-Rubicek H, Kennett D, Judd J, Little A, Moir S, Richmond P, Thompson R. Evaluation in the school development in health education project; a generic process in everyones environment. Paper presented at 18th ACHPER national/international conference, 'Building healthy futures; an environmental challenge', 1991.

McBride N, Midford R (1997) The National Initiatives in Drug Education Project: Western Australia Evaluation Report. Perth: National Centre for Research into the Prevention of Drug Abuse, Curtin University.

Midford R, McBride N (1997) National initiatives in drug education evaluation report. Perth: National Centre for Research into the Prevention of Drug Abuse, Curtin University.

Morris D, Mellor W (1995). Drug Education Needs Assessment: A Marketing Research Presentation. East Sydney: Frank Small and Associates. 
National Drug Strategy Committee (1993) National Drug Strategic Plan 1993-97. Canberra: Australian Government Publishing Service.

National Initiatives in Drug Education (Undated) Evaluation of the National Initiatives in Drug Education Project Consultancy Brief. Department of Health and Family Services.

National Initiatives in Drug Education (NIDE). (Undated) 1995/1996 Business Plan. Department of Health and Family Services.

NSW Management Committee (Undated) National Initiatives in Drug Education 1995/96.Author.

Parlett M, Hamilton D (1972) Evaluation as Illumination: A New Approach to the Study of Innovatory Projects. Edinburgh: Edinburgh University. 


\section{ACKNOWLEDGEMENTS}

The authors would like to convey their appreciation to all key informants and teachers who participated in this evaluation. Their time and insight made the evaluation possible and their goodwill made it a pleasure.

Word Count 6284 
Table 1 Summary of NIDE drug education features across jurisdictions

\begin{tabular}{|c|c|c|c|c|c|c|c|c|}
\hline & ACT & NSW & NT & QLD & SA & TAS & VIC & WA \\
\hline $\begin{array}{l}\text { Substantial pre-existing } \\
\text { drug education } \\
\text { infrastructure and } \\
\text { funding }\end{array}$ & & $\mathrm{X}$ & & $\bar{X}$ & $\mathrm{X}$ & $\mathrm{X}$ & & \\
\hline Participated in Phase 1 & $\mathrm{X}$ & $\mathrm{X}$ & $\mathrm{X}$ & $X$ & $X$ & $X$ & $\mathrm{X}$ & $X$ \\
\hline Participated in Phase 2 & & & $X$ & $X$ & $\mathrm{X}$ & $X$ & $X$ & \\
\hline Participated in Phase 3 & $\mathrm{X}$ & $\mathrm{X}$ & $\mathrm{X}$ & $\mathrm{X}$ & $\mathrm{X}$ & $\mathrm{X}$ & $\mathrm{X}$ & $\mathrm{X}$ \\
\hline $\begin{array}{l}\text { Widespread teacher } \\
\text { training }\end{array}$ & $\mathrm{X}$ & $\mathrm{X}$ & $\mathrm{X}$ & $\mathrm{X}$ & & & $\mathrm{X}$ & \\
\hline $\begin{array}{l}\text { Activity concentrated in } \\
\text { focus schools }\end{array}$ & $\begin{array}{c}\mathrm{X} \\
\text { (phase } \\
3 \text { ) }\end{array}$ & $\begin{array}{c}\mathrm{X} \\
\text { (phase } \\
\text { 3) }\end{array}$ & & & $\mathrm{X}$ & $\mathrm{X}$ & & $\mathrm{X}$ \\
\hline $\begin{array}{l}\text { Emphasised curriculum } \\
\text { development/delivery }\end{array}$ & $\mathrm{X}$ & $\mathrm{X}$ & & $\mathrm{X}$ & $\mathrm{X}$ & & $\begin{array}{c}\mathrm{X} \\
\text { (phase } \\
1 \text { ) }\end{array}$ & \\
\hline $\begin{array}{l}\text { Conducted activity for } \\
\text { parents/community }\end{array}$ & $\mathrm{X}$ & & $\mathrm{X}$ & $\mathrm{X}$ & $\mathrm{X}$ & $\mathrm{X}$ & $\begin{array}{l}\mathrm{X} \\
\text { (phase } \\
\text { 2) }\end{array}$ & $\mathrm{X}$ \\
\hline $\begin{array}{l}\text { Emphasised school based } \\
\text { drug policy development }\end{array}$ & & & $\mathrm{X}$ & & & $\mathrm{X}$ & $X$ & $\mathrm{X}$ \\
\hline $\begin{array}{l}\text { Developed teaching } \\
\text { resources to complement } \\
\text { NIDE material }\end{array}$ & & $\mathrm{X}$ & & $\begin{array}{l}\text { (State } \\
\text { funded) }\end{array}$ & $\mathrm{X}$ & $\mathrm{X}$ & & \\
\hline $\begin{array}{l}\text { Adopted the national } \\
\text { approach to harm } \\
\text { minimisation }\end{array}$ & $\mathrm{X}$ & $\mathrm{X}$ & $\mathrm{X}$ & $\mathrm{X}$ & $\mathrm{X}$ & $\mathrm{X}$ & $X$ & $\begin{array}{l}\text { (Part- } \\
\text { ially) }\end{array}$ \\
\hline
\end{tabular}


Table 2 Numbers of teacher surveys sought and completed

\begin{tabular}{lrc}
\hline & \multicolumn{2}{c}{ Teacher Survey } \\
\hline & Sought & Actual \\
\hline ACT & 30 & 25 \\
NSW & 100 & 79 \\
NT & 30 & 34 \\
QLD & 80 & 49 \\
SA & 30 & 12 \\
TAS & 30 & 19 \\
VIC & 70 & $9 *$ \\
WA & 40 & 26 \\
Total & & \\
\hline
\end{tabular}

*Represents Non government returns only. Government schools did not participate. 
Table 3 Percentage of participants who were aware of the following resources and ratings as to their usefulness

\begin{tabular}{lcccc}
\hline & Do It Booklets & $\begin{array}{c}\text { Candidly } \\
\text { Cannabis }\end{array}$ & $\begin{array}{c}\text { How Will You } \\
\text { Feel } \\
\text { Tomorrow }\end{array}$ & $\begin{array}{c}\text { Harm } \\
\text { Minimis- } \\
\text { ation Video }\end{array}$ \\
\hline $\begin{array}{l}\text { \% of teachers who knew of } \\
\text { resource }\end{array}$ & 23.7 & 63.6 & 77.9 & 48.6 \\
Rating of resource & & & & \\
High & & & & \\
Medium & 4.0 & 33.2 & 33.2 & 15.8 \\
Low & 11.5 & 27.3 & 35.6 & 22.5 \\
& 8.7 & 2.0 & 5.5 & 4.3 \\
\hline
\end{tabular}

Percentages do not add up to 100 because not all respondents knew of resources or because of missing values. 
Table 4

Focus group information on drug education activities undertaken in their schools

\begin{tabular}{|c|c|c|c|c|c|c|c|c|c|c|}
\hline $\begin{array}{l}\text { Drug Education } \\
\text { Activity }\end{array}$ & VIC & $\begin{array}{l}\text { QLD } \\
\text { metro }\end{array}$ & $\begin{array}{l}\text { QLD } \\
\text { cntry }\end{array}$ & TAS & WA & SA & NT & NSW & ACT & Total \\
\hline Policy development & $\mathrm{X}$ & & & $\mathrm{X}$ & $\mathrm{X}$ & & & & & 3 \\
\hline $\begin{array}{l}\text { Drug education } \\
\text { curriculum } \\
\text { development }\end{array}$ & $\mathrm{X}$ & & & $\mathrm{X}$ & & $\mathrm{X}$ & & & $\mathrm{X}$ & 4 \\
\hline $\begin{array}{l}\text { Became more skilled in } \\
\text { delivering drug/health } \\
\text { education }\end{array}$ & & & & $\mathrm{X}$ & $\mathrm{X}$ & $\mathrm{X}$ & & $\mathrm{X}$ & & 4 \\
\hline $\begin{array}{l}\text { 'In-house' drug } \\
\text { education training to } \\
\text { other school staff }\end{array}$ & $\mathrm{X}$ & & & & & $\mathrm{X}$ & & $\mathrm{X}$ & $\mathrm{X}$ & 4 \\
\hline $\begin{array}{l}\text { Parental involvement/ } \\
\text { training }\end{array}$ & & & $\mathrm{X}$ & $\mathrm{X}$ & $\mathrm{X}$ & $\mathrm{X}$ & $\mathrm{X}$ & & $\mathrm{X}$ & 6 \\
\hline $\begin{array}{l}\text { Raised } \\
\text { awareness/support for } \\
\text { drug education }\end{array}$ & $\mathrm{X}$ & $\mathrm{X}$ & $\mathrm{X}$ & $\mathrm{X}$ & & $\mathrm{X}$ & $\mathrm{X}$ & & $\mathrm{X}$ & 7 \\
\hline $\begin{array}{l}\text { Increased wider } \\
\text { community involvement } \\
\text { in delivery of drug } \\
\text { education }\end{array}$ & $\mathrm{X}$ & & $\mathrm{X}$ & $\mathrm{X}$ & $\mathrm{X}$ & $\mathrm{X}$ & $\mathrm{X}$ & $\mathrm{X}$ & $\mathrm{X}$ & 8 \\
\hline
\end{tabular}

